\title{
Differential effect of cholesterol on type I and II feline coronavirus infection
}

\author{
Tomomi Takano $^{1} \cdot$ Yui Satomi $^{1} \cdot$ Yuu Oyama ${ }^{1} \cdot$ Tomoyoshi Doki $^{1}$ • \\ Tsutomu Hohdatsu ${ }^{1}$
}

Received: 27 August 2015/ Accepted: 19 October 2015/Published online: 29 October 2015

(C) Springer-Verlag Wien 2015

\begin{abstract}
Feline infectious peritonitis (FIP) is a fatal disease of domestic and wild felidae that is caused by feline coronavirus (FCoV). FCoV has been classified into types I and II. Since type I FCoV infection is dominant in the field, it is necessary to develop antiviral agents and vaccines against type I FCoV infection. However, few studies have been conducted on type I FCoV. Here, we compare the effects of cholesterol on types I and II FCoV infections. When cells were treated methyl- $\beta$-cyclodextrin $(\mathrm{M} \beta \mathrm{CD})$ and inoculated with type $\mathrm{I} F \mathrm{FoV}$, the infection rate decreased significantly, and the addition of exogenous cholesterol to $\mathrm{M} \beta C D$-treated cells resulted in the recovery of the infectivity of type I FCoV. Furthermore, exogenous cholesterol increased the infectivity of type I FCoV. In contrast, the addition of $\mathrm{M} \beta \mathrm{CD}$ and exogenous cholesterol had little effect on the efficiency of type II FCoV infection. These results strongly suggest that the dependence of infection by types I and II FCoV on cholesterol differs.
\end{abstract}

\section{Introduction}

Coronaviruses are single-positive-strand RNA viruses with a genome size of approximately $30 \mathrm{kbp}$, belonging to the family Coronaviridae, subfamily Coronavirinae. The subfamily Coronavirinae has been further classified into four genera: Alphacoronavirus, Betacoronavirus, Gammacoronavirus, and Deltacoronavirus [6]. In cats, feline

Tsutomu Hohdatsu

hohdatsu@vmas.kitasato-u.ac.jp

1 Laboratory of Veterinary Infectious Disease, School of Veterinary Medicine, Kitasato University, Towada, Japan coronavirus (FCoV) of the genus Alphacoronavirus has been identified.

The FCoV virion is mainly composed of nucleocapsid $(\mathrm{N})$, envelope (E), membrane (M), and peplomer spike (S) proteins [6]. There are two genotypes/serotypes of FCoV: FCoV has been classified into types I and II based on the amino acid sequence of its $\mathrm{S}$ protein $[10,19]$. Type II FCoV was previously suggested to be produced by recombination between type I FCoV and type II canine coronavirus $(\mathrm{CCoV})[7,31]$. Separate from these genotypes/serotypes, FCoV has been classified into two biotypes: weakly pathogenic feline enteric coronavirus (FECV; low-virulent FCoV) and strongly pathogenic feline infectious peritonitis virus (FIPV; virulent FCoV) [20]. The etiology of the pathogenesis of FECV/FIPV has not yet been elucidated in detail. Two theories currently exist: an "internal mutation theory" and a "circulating virulent/ avirulent theory" $[1,3,21]$. FIPV causes a fatal disease called FIP in wild and domestic cats [20]. Although antiviral agents and vaccines against FIPV infection have been investigated, no method has yet been established for practical use.

Since type I FCoV infection is dominant in the field [9, $16,18,26]$, antiviral agents and vaccines need to be developed against type I FCoV infection. However, type II FCoV is mainly used in studies on FIP because the propagation of type I FCoV in feline cell lines and monocytes/macrophages is weaker than that of type II FCoV. Although recombinant type I FCoV has recently been prepared by reverse genetics [30], studies on type I FCoV have not progressed. Differences have been identified in the following events between types I and II FCoV: replicative ability in cell lines and monocytes/macrophages [29], the amino acid sequence and immunogenicity of the $S$ protein $[10,19]$, and the virus receptor used to enter cells 
$[4,8]$. However, differences in other events remain unclear, and the virus receptor for type I FCoV has not yet been identified.

Cholesterol is an essential component in animal cells [12]. It has been shown to play a role in viral infection of cells. For example, host cell cholesterol levels have been shown to influence the replication of human hepatitis $\mathrm{C}$ virus (HCV), human immunodeficiency virus, and dengue virus $[14,17,36]$, but not that of vesicular stomatitis virus (VSV) [13, 22]. Furthermore, cholesterol contained in the envelope of influenza virus has been shown to affect infection of cells [27]. Cholesterol contained in host cells was previously reported to be involved in host cell infection by mouse hepatitis virus (MHV) and severe acute respiratory syndrome coronavirus (SARS-CoV) [5, 33], which, like FCoV both belong to the family Coronaviridae. Transmissible gastroenteritis virus (TGEV) and type II $\mathrm{CCoV}$ infections involve cellular and viral cholesterol [23, 25]. The $\mathrm{S}$ protein of type II $\mathrm{FCoV}$ is homologous to those of TGEV and type II CCoV, and the infection of cells by type II FCoV was previously shown to be only slightly influenced by cholesterol [35]. On the other hand, the relationship between type I FCoV and cholesterol remains to be investigated.

In the present study, we determined whether cellular and viral cholesterol levels influenced the infectivity of FCoV types I and II in cell culture.

\section{Materials and methods}

\section{Cell cultures and viruses}

Felis catus whole fetus (fcwf)-4 cells (kindly supplied by Dr. M. C. Horzinek of State University of Utrecht) were grown in Eagle's minimum essential medium containing $50 \%$ L-15 medium, $5 \%$ fetal calf serum (FCS), and $100 \mathrm{U}$ of penicillin and $100 \mu \mathrm{g}$ of streptomycin per ml. The type I FCoV KU-2 strain (FCoV-I KU-2) was isolated in our laboratory, and the type I FCoV Black strain (FCoV-I Black) and the type I FCoV UCD-1 strain (FCoV-I UCD-1) were kindly supplied by Dr. J. K. Yamamoto of the University of Florida. The type II FCoV 79-1146 strain (FCoV-II 79-1146) was kindly provided by Dr. M. C. Horzinek. VSV (New Jersey strain) was obtained from the Laboratory of Veterinary Microbiology at Kitasato University. These viruses were grown in fcwf-4 cells at $37{ }^{\circ} \mathrm{C}$.

\section{Compounds}

Methyl- $\beta$-cyclodextrin $(\mathrm{M} \beta \mathrm{CD})$ and water-soluble cholesterol were obtained from Sigma Aldrich (USA). These compounds were diluted to the desired concentrations in maintenance medium.

\section{Detection of cellular cholesterol}

The cellular cholesterol content of fcwf- 4 cells was evaluated using a Cholesterol Cell-Based Detection Assay Kit (Cayman Chemical, USA) according to the manufacturer's instructions. Briefly, fcwf-4 cells were grown on an 8-well Lab-Tek Chamber Slide (Thermo Fisher Scientific, USA). Confluent fcwf-4 cell monolayers were cultured in medium containing $16 \mathrm{mM} \mathrm{M} \beta C D$ at $37^{\circ} \mathrm{C}$ for $30 \mathrm{~min}$. After washing with PBS, cells were cultured in medium containing $0.5 \mathrm{mg}$ of water-soluble cholesterol per $\mathrm{ml}$ at $37{ }^{\circ} \mathrm{C}$ for $30 \mathrm{~min}$. After fixing and staining, filipin-III-binding cells were analyzed using a Leica FW4000 fluorescence microscope (Germany).

\section{Cytotoxic effects of compounds}

Cell viability was measured using a WST- 8 assay, as described previously [28]. Briefly, fcwf-4 cells were seeded in 96-well plates. M $\beta C D$ or water-soluble cholesterol was added in triplicate to the wells. After 48 hours, the culture supernatants were removed, WST-8 solution (WST-8 Cell Proliferation Assay Kit; Kishida Chemical Co., Ltd., Japan) was added, and the cells were returned to the incubator for 1 hour. The absorbance of formazan produced was measured at $450 \mathrm{~nm}$ using a 96-well spectrophotometric plate reader as described by the manufacturer. Cytotoxicity was calculated using the following formula: Cytotoxicity $(\%)=[(\mathrm{OD}$ of untreated cells - compound-treated cells $) /$ (OD of compound-untreated cells)] $\times 100$.

\section{Effects of cellular cholesterol depletion on FCoV infection in fcwf- 4 cells}

The method for the depletion of cholesterol from cells was modified from that described by Ren et al. [25]. Briefly, confluent fcwf-4 cell monolayers were cultured in medium containing $\mathrm{M} \beta \mathrm{CD}$ ranging from 0 to $16 \mathrm{mM}$ in 24-well multi-plates at $37{ }^{\circ} \mathrm{C}$ for $30 \mathrm{~min}$. After washing with phosphate-buffered saline (PBS), the virus (multiplicity of infection [MOI], 0.01) was adsorbed into the cells at $37{ }^{\circ} \mathrm{C}$ for 1 hour. After washing, cells were cultured in maintenance medium with $1.5 \%$ carboxymethyl cellulose (CMC-MEM). Cell monolayers were incubated at $37{ }^{\circ} \mathrm{C}$ for 48 hours, fixed, and stained with $1 \%$ crystal violet solution containing $10 \%$ buffered formalin, and the plaques were then counted. The percentage of plaque decrease or increase was determined using the following formula: Percentage of the plaque number $(\%)=[$ (plaque number of compound-treated cells $) /$ (plaque number of untreated cells) $] \times 100$. 


\section{Effects of cellular cholesterol replenishment on FCoV infection in fcwf- 4 cells}

The method of replenishment of cholesterol-depleted cells was modified from that described by Ren et al. [25]. Briefly, confluent fcwf- 4 cell monolayers were cultured in medium containing $16 \mathrm{mM} \mathrm{M} \beta C D$ in 24-well multi-plates at $37{ }^{\circ} \mathrm{C}$ for $30 \mathrm{~min}$. After washing with PBS, cells were cultured in medium containing water-soluble cholesterol ranging from 0 to $2.5 \mathrm{mg} / \mathrm{ml}$ at $37^{\circ} \mathrm{C}$ for $30 \mathrm{~min}$. Cells were washed and the virus (MOI, 0.01) was adsorbed onto the cells at $37{ }^{\circ} \mathrm{C}$ for 1 hour. After washing, cells were cultured in CMC-MEM or medium without carboxymethyl cellulose (MEM). In the case of cultured in CMC-MEM, the cell monolayers were incubated at $37{ }^{\circ} \mathrm{C}$ for 48 hours, fixed, and stained with $1 \%$ crystal violet solution containing $10 \%$ buffered formalin, and the resulting plaques were then counted. The percentage of plaques (\%) was determined by the method described above. When MEM was used, the culture supernatants were collected 48 hours postinfection, and virus titers were determined by the $\mathrm{TCID}_{50}$ assay.

\section{Immunofluorescence assay}

fcwf-4 cells were grown on an 8-well Lab-Tek chamber slide (Thermo Fisher Scientific, USA). Confluent fcwf-4 cell monolayers were cultured in medium containing $16 \mathrm{mM}$ of $\mathrm{M} \beta \mathrm{CD}$ at $37^{\circ} \mathrm{C}$ for $30 \mathrm{~min}$. After washing with PBS, cells were cultured in medium containing $0.5 \mathrm{mg}$ of water-soluble cholesterol per $\mathrm{ml}$ at $37^{\circ} \mathrm{C}$ for $30 \mathrm{~min}$. Cells were washed, and the virus (MOI, 0.01) was adsorbed into the cells at $37{ }^{\circ} \mathrm{C}$ for 1 hour. After washing, cells were cultured in MEM. The cell monolayers were incubated at $37{ }^{\circ} \mathrm{C}$. After 12 hours, $\mathrm{N}$ protein levels were determined by an immunofluorescence assay (IFA) as described previously [11].

\section{Effects on infectivity of depletion and replenishment of cholesterol from the virus}

The method for depletion and replenishment of cholesterol from the virus was modified from that described by Pratelli and Colao [23]. Briefly, the virus (MOI, 0.1) was incubated with medium containing $16 \mathrm{mM} \mathrm{M} \beta \mathrm{CD}$ at $37{ }^{\circ} \mathrm{C}$ for 1 hour. In order to specifically determine whether cholesterol depletion by $\mathrm{M} \beta C \mathrm{CD}$ affected the number of plaques caused by FCoV, M $\beta C D$-treated FCoV was adsorbed onto the cells at $37{ }^{\circ} \mathrm{C}$ for 1 hour. M $\beta C D$-treated viral suspensions were diluted 1:9 in medium before infection to avoid the carry-over effects of $\mathrm{M} B \mathrm{CD}$ on fcwf- 4 cells. After washing, cells were cultured in CMC-MEM or MEM. In order to analyze infection efficiency after viral cholesterol replenishment, the virus (MOI, 0.1) was incubated with medium containing $16 \mathrm{mM} \mathrm{M} \beta \mathrm{CD}$ at $37{ }^{\circ} \mathrm{C}$ for $30 \mathrm{~min}$. $\mathrm{M} \beta C D$-treated viral suspensions were then incubated with medium containing water-soluble cholesterol ranging from 0 to $2.5 \mathrm{mg} / \mathrm{ml}$ at $37{ }^{\circ} \mathrm{C}$ for 1 hour. Cholesterol- and M $\beta C D$-treated FCoV were adsorbed onto cells at $37{ }^{\circ} \mathrm{C}$ for 1 hour in order to specifically determine whether cholesterol replenishment affected the number of plaques caused by FCoV. In an attempt to avoid the carry-over effects of cholesterol and $\mathrm{M} \beta \mathrm{CD}$ on fcwf-4 cells, cholesterol- and M $\beta C D$-treated viral suspensions were diluted 1:9 in medium before infection. Cells were washed, and the virus was adsorbed onto the cells at $37{ }^{\circ} \mathrm{C}$ for 1 hour. After washing, cells were cultured in CMC-MEM at $37{ }^{\circ} \mathrm{C}$ for 48 hours. The cells were fixed and stained with $1 \%$ crystal violet solution containing $10 \%$ buffered formalin, and the resulting plaques were counted. The number of plaques, expressed as a percentage of the control, was measured by the method described above.

\section{Statistical analysis}

Data from only two groups were analyzed by Student's $t$ test (Welch's t-test or Bartlett's test), and multiple groups were analyzed by one-way ANOVA followed by Tukey's test.

\section{Results}

\section{The cytotoxic effects of $M \beta C D$ and exogenous cholesterol}

The cytotoxic effects of M $\beta C D$ and exogenous cholesterol in fcwf- 4 cells are shown in Tables 1 and 2. Exogenous cholesterol slightly exhibited cytotoxicity at $5 \mathrm{mg} / \mathrm{ml}$.

\section{Effects of MPCD and exogenous cholesterol on cellular membranes}

We investigated changes in the cellular cholesterol content of fcwf-4 cells treated with $\mathrm{M} \beta C D$ and water-soluble cholesterol (exogenous cholesterol) using filipin III as a fluorescent stain for cholesterol. Cellular cholesterol levels specifically decreased in fcwf-4 cells treated with $16 \mathrm{mM}$ $\mathrm{M} \beta \mathrm{CD}$ (Fig. 1A and B) and slightly decreased in cells treated with $4 \mathrm{mM} \mathrm{M} \beta C D$ (data not shown). The cellular cholesterol level in fcwf-4 cells treated with $16 \mathrm{mM}$ $\mathrm{M} \beta C \mathrm{CD}$ followed by the addition of $0.5 \mathrm{mg} / \mathrm{ml}$ of exogenous cholesterol returned to a level similar to that in untreated-fcwf-4 cells (Fig.1A and C). 
Table 1 Cytotoxic effects of M $\beta C D$ in fcwf-4 cells

\begin{tabular}{lllllll}
\hline & \multicolumn{3}{l}{$\mathrm{M} \beta \mathrm{CD}(\mu \mathrm{M})$} & & & \\
\cline { 2 - 6 } & 0 & 2 & 4 & 8 & 16 & 32 \\
\hline Cell viability $(\%)$ & $98.7 \pm 1.6^{1)}$ & $100.7 \pm 3.0^{1)}$ & $97.7 \pm 1.8^{1)}$ & $98.6 \pm 2.1^{1)}$ & $98.4 \pm 3.3^{1)}$ & $96.3 \pm 2.6^{1)}$ \\
\hline
\end{tabular}

1) Cell viability ( $\%$ mean $\pm \mathrm{SE}) ; \mathrm{n}=3$

Table 2 Cytotoxic effects of exogenous cholesterol (water-soluble cholesterol) in fcwf-4 cells

\begin{tabular}{lllllll}
\hline & \multicolumn{5}{l}{ Exogenous cholesterol $(\mathrm{mg} / \mathrm{ml})$} \\
\cline { 2 - 6 } & 0 & 0.1 & 0.5 & 1.0 & 2.5 & 5 \\
\hline Cell viability $(\%)$ & $99.1 \pm 1.9^{1)}$ & $98.5 \pm 1.8^{1)}$ & $98.9 \pm 1.7^{1)}$ & $96.9 \pm 2.3^{1)}$ & $91.9 \pm 2.5^{1)}$ & $80.2 \pm 7.3^{1)}$ \\
\hline
\end{tabular}

1) Cell viability (\% mean $\pm \mathrm{SE}) ; \mathrm{n}=3$

Fig. 1 Effects of $M \beta C D$ and exogenous cholesterol on cellular membrane content. Fcwf-4 cells were incubated with $16 \mathrm{mM} \mathrm{M} \beta \mathrm{CD}$ at $37{ }^{\circ} \mathrm{C}$ for $30 \mathrm{~min}$. After washing, cells were incubated with $0.5 \mathrm{mg}$ of cholesterol per $\mathrm{ml}$. The cellular cholesterol content of fcwf- 4 cells was evaluated using a filipincholesterol stain. (A) Untreated cells, (B) cholesterol-depleted cells $(M \beta C D$-treated cells that were then incubated with vehicle), and (C) cholesterolreplenished cells $(\mathrm{M} \beta \mathrm{CD}$ treated cells that were then incubated with exogenous cholesterol)
(A)

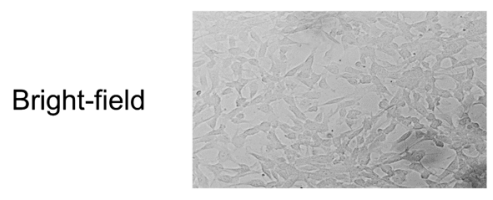

Filipin III

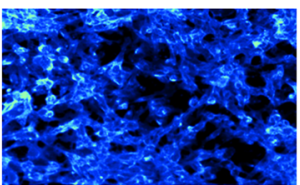

Merge

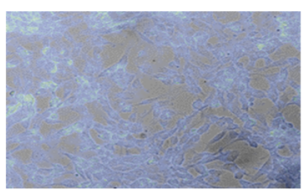

$\mathrm{M} \beta C D(\mathrm{mM})$

Cholesterol $(\mathrm{mg} / \mathrm{ml})$

\section{Efficiency of depletion and replenishment of cellular cholesterol on FCoV}

In order to confirm the effects of the cellular depletion of cholesterol on FCoV infection, fcwf-4 cells were pretreated with $\mathrm{M} \beta C D$ ranging from $0 \mathrm{mM}$ to $16 \mathrm{mM}$, followed by virus inoculation. The number of plaques caused by FCoVI KU-2 was reduced by $\mathrm{M} \beta \mathrm{CD}$ treatment in a dose-dependent manner (Fig. 2). The number of plaques caused by FCoV-II 79-1146 was reduced in cells treated with $16 \mathrm{mM}$ $\mathrm{M} \beta \mathrm{CD}$ but did not show a significant difference between treatment and control $(0 \mathrm{mM} \mathrm{M} \beta \mathrm{CD})$. In contrast, the number of plaques caused by VSV was not affected by pretreatment with $\mathrm{M} \beta C D$. Cholesterol-depleted fcwf-4 cells were replenished by addition of exogenous cholesterol before virus inoculation in order to determine whether cellular cholesterol is important for FCoV-I infection. The cholesterol.
(B)
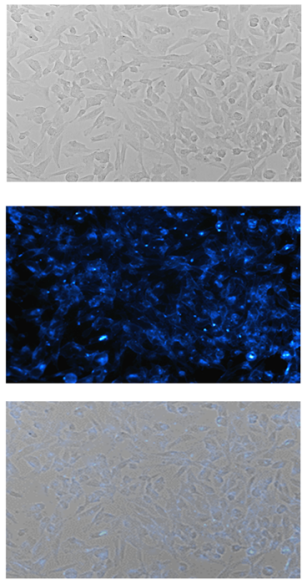

16

0
(C)
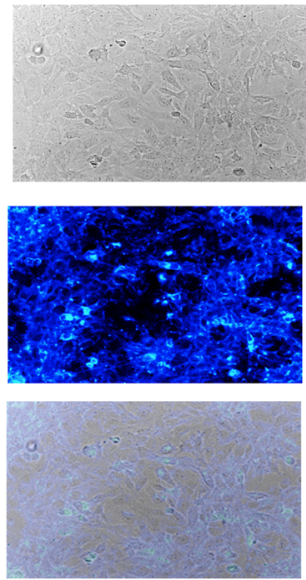

16

0.5

number of plaques caused by FCoV-I KU-2 was increased by treatment with exogenous cholesterol in a dose-dependent manner (Fig. 3). In contrast, the number of plaques caused by FCoV-II 79-1146 increased slightly, but VSV was not affected by replenishment with exogenous

The influence of cellular cholesterol on the replication of other type I FCoVs was investigated. The number of plaques caused by FCoV-I KU-2, FCoV-I Black, and FCoV-I UCD-1 was reduced by treatment with $16 \mathrm{mM}$ $\mathrm{M} \beta \mathrm{CD}$ (Fig. 4A). However, exogenous cholesterol restored the number of plaques caused by these viruses in a dose-dependent manner. When $0.5 \mathrm{mg}$ of exogenous cholesterol per $\mathrm{ml}$ was added, the number of plaques caused by FCoV-I Black and FCoV-I UCD-1 was significantly higher than without treatment with $\mathrm{M} \beta C D$ and exogenous cholesterol. In contrast, cellular cholesterol 
Fig. 2 Efficiency of $M \beta C D$ on FCoV and VSV infections. fcwf-4 cell monolayers were cultured with $\mathrm{M} \beta \mathrm{CD}$, followed by inoculation with the virus, and plaques were counted. The percentage of the plaque number was verified by a plaque assay on fcwf- 4 cells. The results are shown as means $\pm \operatorname{SE}(\mathrm{n}=4)$

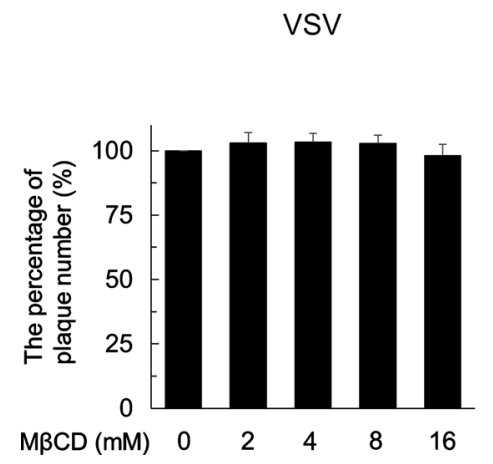

FIPV-I KU-2

FIPV-II 79-1146
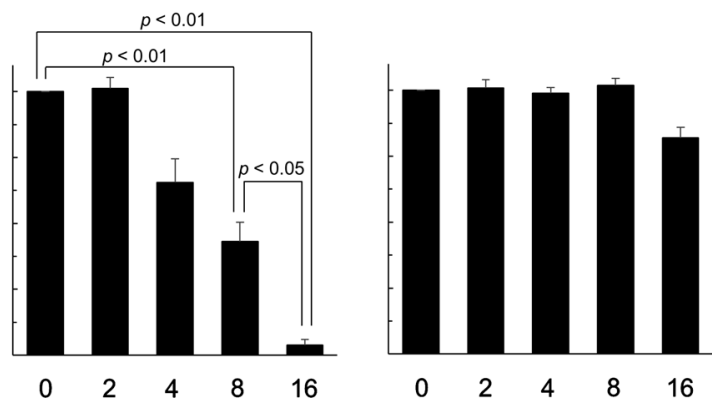

Fig. 3 Efficiency of depletion and replenishment of cellular cholesterol in FCoV and VSV infections. fcwf-4 cell monolayers were cultured with $\mathrm{M} \beta C D$ and replenished with water-soluble cholesterol followed by inoculation with the virus, and plaques were counted. The results are shown as means $\pm \operatorname{SE}(\mathrm{n}=4)$
VSV

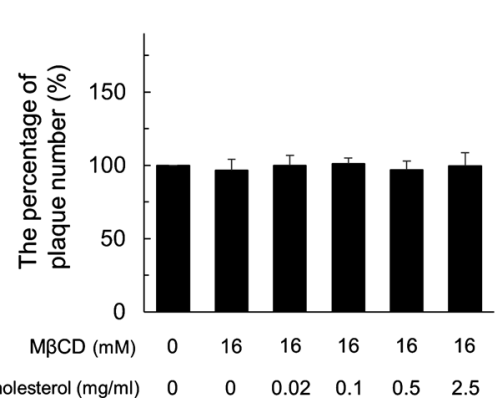

FIPV-I KU-2

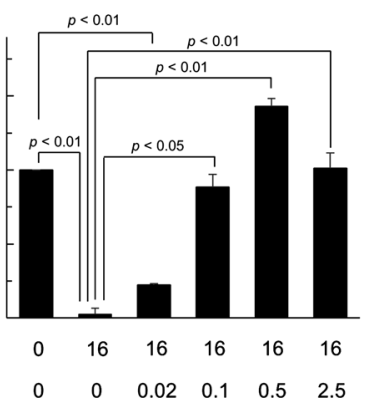

FIPV-II 79-1146

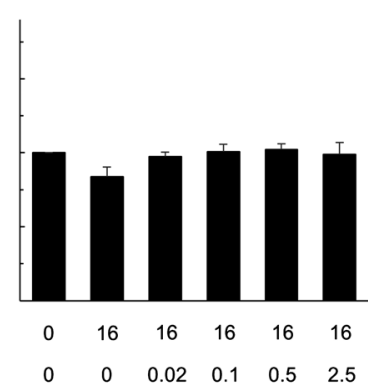

Fig. 4 A. Efficiency of depletion and replenishment of cellular cholesterol in type I FCoV infection. fcwf-4 cell monolayers were cultured with $\mathrm{M} \beta \mathrm{CD}$ and replenished with water-soluble cholesterol, followed by an inoculation with the virus, and plaques were counted. The results are shown as means $\pm \operatorname{SE}(n=4)$. B. Measurement of FCoV titers in supernatants of cholesteroldepleted and -replenished fcwf4 cells. fcwf- 4 cell monolayers were cultured with $\mathrm{M} \beta \mathrm{CD}$ and replenished with water-soluble cholesterol followed by an inoculation with the virus, and the virus titer was determined by $\mathrm{TCID}_{50}$ assay. The results are shown as means $\pm \mathrm{SE}$ $(\mathrm{n}=4)$
(A)
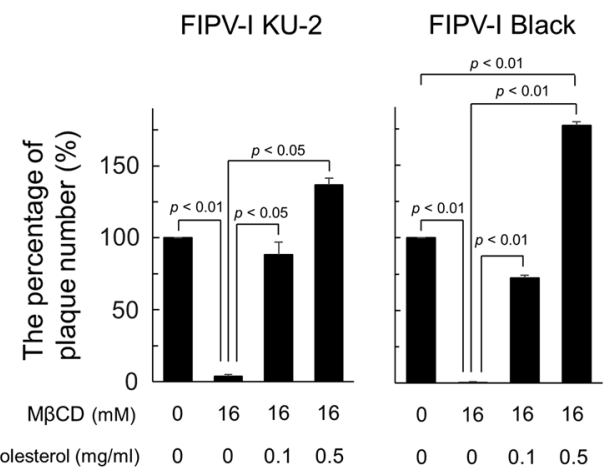

(B)

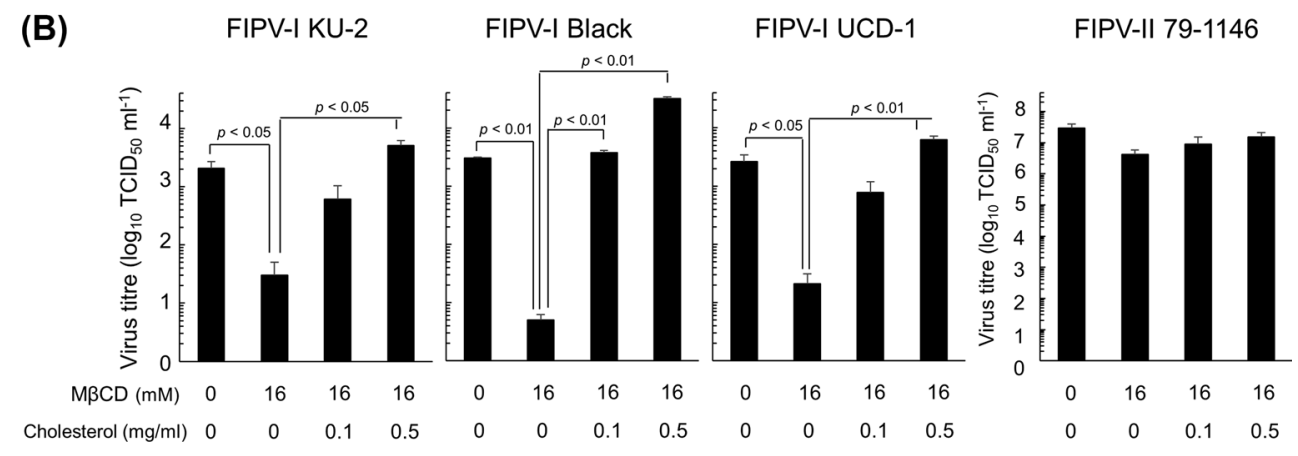

FIPV-II 79-1146
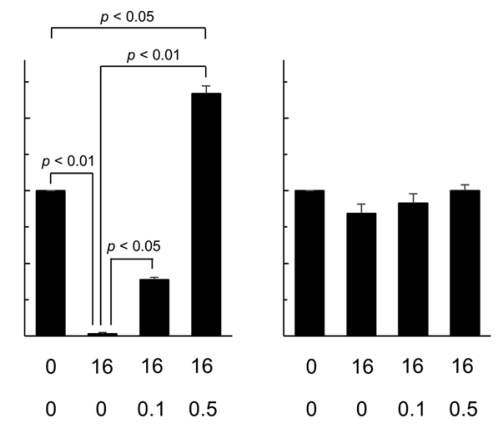

FIPV-II 79-1146 depletion and replenishment only slightly affected the number of plaques caused by FCoV-II 79-1146. In order to determine the amount of FCoV released into the supernatant of cholesterol-depleted and -replenished cells, we measured virus titers in culture supernatants using the
TCID $_{50}$ assay. The titers of FCoV-I KU-2, FCoV-I Black, and FCoV-I UCD-1 in the supernatant of MBCD-treated cells were significantly decreased by approximately 100-fold (Fig. 4B), and exogenous cholesterol restored the titers of these viruses in a dose-dependent manner. In 
contrast to type I FCoVs, the cellular depletion and replenishment of cholesterol slightly affected the titer of FCoV-II 79-1146 in the supernatant of fcwf-4 cells. We investigated the expression of viral proteins in order to further investigate the effects of cholesterol on $\mathrm{FCoV}$ infectivity. The $\mathrm{N}$ protein levels of FCoV-I KU-2 specifically decreased in fcwf-4 cells treated with $16 \mathrm{mM} \mathrm{M} \beta \mathrm{CD}$ (Fig. 5). The $\mathrm{N}$ protein levels of fcwf-4 cells treated with $16 \mathrm{mM} \mathrm{M} \beta C D$, followed by the addition of $0.5 \mathrm{mg}$ of exogenous cholesterol per ml, returned to levels similar to those in untreated-fcwf-4 cells. In contrast to type I FCoV $\mathrm{KU}-2$, the depletion and replenishment of cellular cholesterol did not affect the N protein levels of FCoV-II 79-1146 in fcwf-4 cells.

\section{Facilitation of type I FCoV infection by the addition of cholesterol to fcwf-4 cells}

As shown in Figure 4, number of plaques caused by type-I FCoV increased in exogenous-cholesterol-treated fcwf-4 cells. In order to confirm the influence of cholesterol on type-I FCoV in cells untreated with $\mathrm{M} \beta \mathrm{CD}$, untreated cells were incubated with exogenous cholesterol and then inoculated with the virus. Incubation with 0.1 and $0.5 \mathrm{mg}$ of exogenous cholesterol per ml significantly increased the number of plaques caused by FCoV-I KU-2, FCoV-I Black, and FCoV-I UCD-1 (Fig. 6A). However, addition of $2.5 \mathrm{mg}$ of exogenous cholesterol per $\mathrm{ml}$ did not increase the number of plaques caused by type-I FCoV. Virus titers in culture supernatants showed similar changes; however, no significant differences were noted (Fig. 6B).

\section{Efficiency of depletion and replenishment of cholesterol in virions}

In order to confirm the effects of cholesterol depletion on the envelope of FCoV, the virus was treated with $16 \mathrm{mM}$
$\mathrm{M} \beta C D$ prior to inoculation. Treatment with $\mathrm{M} \beta C D$ reduced the number of plaques caused by FCoV-I KU-2 (Fig. 7), and exogenous cholesterol restored the number of plaques caused by FCoV-I KU-2 in a dose-dependent manner; however, no significant differences were noted (Fig. 7). In contrast to FCoV-I KU-2, viral cholesterol depletion and replenishment did not affect the number of plaques caused by FCoV-II 79-1146.

\section{Discussion}

Between 70 and $98 \%$ of FCoV-infected cats in the field have been reported to be infected with type I FCoV [9, 16, 18, 26]. This finding demonstrates that type I FCoV needs to be examined in more detail in studies on the prevention and treatment of feline FCoV infection. However, no study using type I FCoV has been conducted to date because the propagation of type I FCoV in feline cell lines is low. Type II FCoV uses feline aminopeptidase $\mathrm{N}$ (fAPN) as a receptor [8, 34], and infection of cells with this virus has been studied in detail. In contrast, the virus receptor for type I FCoV has not been identified, and the mechanism underlying cell infection has not yet been elucidated. Therefore, a basic analysis of type I FCoV is needed for the development of effective antiviral drugs against type I FCoV, which is prevalent in the field. In the present study, we discovered that the dependence of the infection on cholesterol differs between types I and II FCoV. We recently reported that the rate of inhibition of viral replication by a viroporin inhibitor differed between types I and II FCoV [28]. Based on these findings, it is desirable to use type I FCoV, in addition to type II FCoV, for the development of effective antiviral drugs.

We depleted cellular cholesterol in fcwf-4 cells using $\mathrm{M} \beta \mathrm{CD}$. Cell membrane cholesterol is extracted by binding to the hydrophobic cores of $\mathrm{M} \beta C D$ [15]. Nystatin is
Fig. 5 Effects of $\mathrm{M} \beta \mathrm{CD}$ and exogenous cholesterol on the FCoV N protein. Fcwf-4 cells were incubated with $16 \mathrm{mM}$ $\mathrm{M} \beta \mathrm{CD}$ at $37^{\circ} \mathrm{C}$ for $30 \mathrm{~min}$. After washing, cells were incubated with $0.5 \mathrm{mg}$ of cholesterol per ml. FCoV N protein was evaluated with IFA

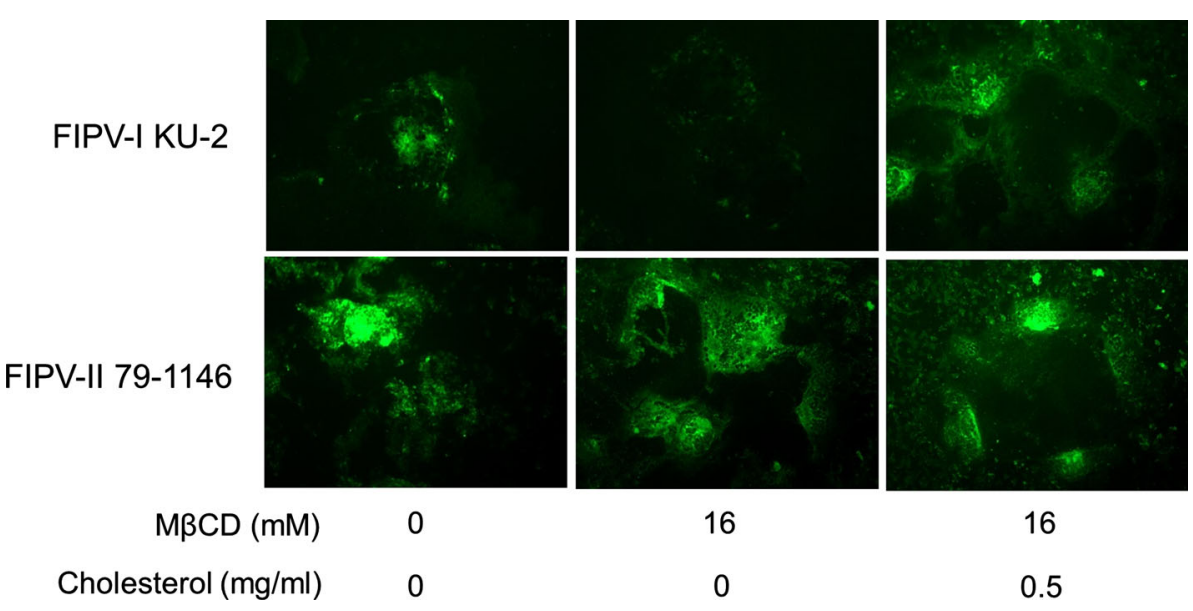



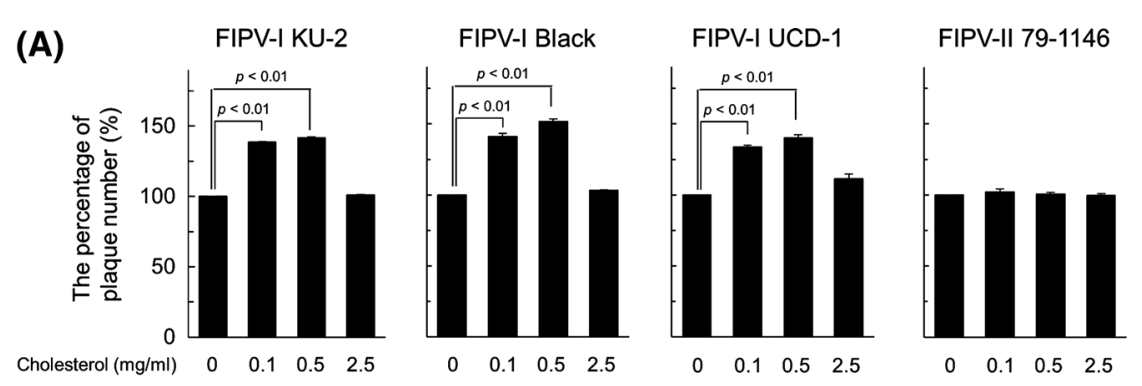

(B)
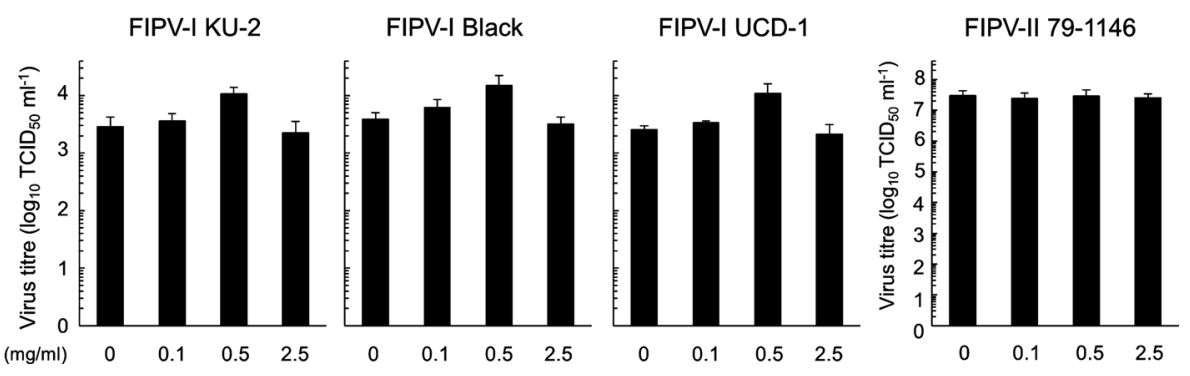

Fig. 6 A. Facilitation of type I FCoV infection by the addition of cholesterol to fcwf- 4 cells. fcwf- 4 cells were cultured in medium containing water-soluble cholesterol ranging from 0 to $2.5 \mathrm{mg} / \mathrm{ml}$ at $37{ }^{\circ} \mathrm{C}$ for $30 \mathrm{~min}$. After washing, the virus (MOI, 0.01) was adsorbed onto the cells at $37{ }^{\circ} \mathrm{C}$. After $1 \mathrm{~h}$, cells were cultured in CMC-MEM for $48 \mathrm{~h}$, and plaques were counted. The results are shown as means $\pm \mathrm{SE}(\mathrm{n}=4)$. B. Measurement of FCoV titers in supernatants

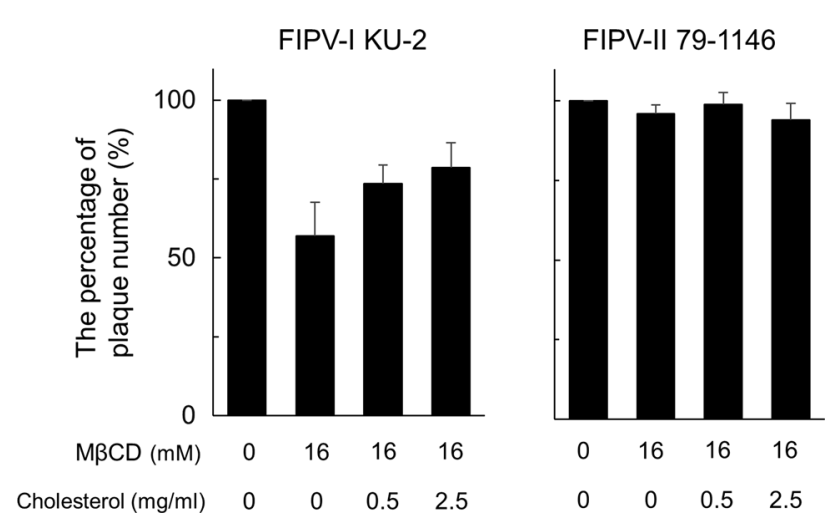

Fig. 7 Efficiency of depletion and replenishment of cholesterol in virions. FCoV was incubated with $M \beta C D$ and replenished with watersoluble cholesterol, and plaques were counted. The results are shown as means $\pm \operatorname{SE}(n=4)$

frequently used, as well as $\mathrm{M} \beta \mathrm{CD}$, to analyze cholesteroldependent viral cell infection; however, it sequesters, rather than removes cell membrane cholesterol [32]. Moreover, strong cytotoxicity was noted in fcwf-4 cells treated with nystatin in a preliminary experiment. Therefore, we selected $\mathrm{M} \beta \mathrm{CD}$.

The involvement of cholesterol in the entry of an enveloped virus has been reported previously [24]. Based on the type of cholesterol dependence they display, viruses can be divided into four groups: i) envelope cholesterol (e.g., influenza virus) [27], ii) cell membrane cholesterol of cholesterol-treated fcwf-4 cells. fcwf-4 cells were cultured in medium containing water-soluble cholesterol ranging from 0 to $2.5 \mathrm{mg} / \mathrm{ml}$ at $37^{\circ} \mathrm{C}$ for $30 \mathrm{~min}$. After washing, the virus (MOI, 0.01) was adsorbed onto the cells at $37^{\circ} \mathrm{C}$. After $1 \mathrm{~h}$, cells were cultured in MEM for $48 \mathrm{~h}$, and virus titers in culture supernatants were measured. The results are shown as means $\pm \operatorname{SE}(n=4)$

(e.g., Ebola virus) [2], iii) both envelope and cell membrane cholesterol (e.g., human immunodeficiency virus) [36], and iv) no cholesterol involvement in cell infection (e.g., VSV) [13, 22]. The coronaviruses MHV and SARS$\mathrm{CoV}$ of the genus Betacoronavirus belong to the second group [5, 33], while TGEV and type II canine coronavirus (CCoV) of the genus Alphacoronavirus belong to the third group [23, 25]. Based on our results, type I FCoV belongs to the second or third group, and type II FCoV belongs to the second or fourth group, suggesting that the cholesterol dependence of infection differs between FCoV types I and II.

M $\beta C D$ slightly inhibited type II FCoV replication. A previous report showed that cholesterol had a slight effect on infection by FCoV-II 79-1146. It has been suggested that type II FCoV does not require much cholesterol for infection.

The virus receptor for type II FCoV is fAPN [8, 34], whereas that for type I FCoV has not yet been identified. Tekes et al. [29] suggested that fAPN functions as a virus receptor for type I FCoV, although it is very inefficient. Based on this hypothesis, type I FCoV might enter cells using fAPN and a cofactor (coreceptor). MHV fuses with the cell membrane, utilizing cholesterol after binding to carcinoembryonic antigen-related cell adhesion molecule (CEACAM), and enters cells using cholesterol in the absence of CEACAM [33]. Cholesterol may also function as an essential cofactor in type I FCoV infection. 
Furthermore, the envelope cholesterol of type I FCoV has been suggested to be involved in infection, as shown in Figure 7. Further investigations are needed in order to determine whether the envelope cholesterol of type I FCoV plays an important role in cell infection.

Although it currently remains unclear whether the results of the present study provide direct evidence regarding the cell entry mechanism of field strains of type I FCoV, they may be useful for determining the mechanism responsible. Previous studies on the FCoV replication mechanism were mainly performed using type II FCoV. Therefore, our study may be more useful than previous studies using type II FCoV for elucidating the cell entry mechanism of field strains of type I FCoV.

In this study, the dependence of the infection on cholesterol markedly differed between types I and II FCoV. Since type I FCoV is dominant in the field, studies using type I FCoV are desirable. Our results may be useful for obtaining a deeper understanding of type I FCoV.

Acknowledgments This work was supported by JSPS KAKENHI grant number 25292183.

\section{References}

1. Barker EN, Tasker S, Gruffydd-Jones TJ, Tuplin CK, Burton K, Porter E, Day MJ, Harley R, Fews D, Helps CR, Siddell SG (2013) Phylogenetic analysis of feline coronavirus strains in an epizootic outbreak of feline infectious peritonitis. J Vet Intern Med 27:445-450

2. Bavari S, Bosio CM, Wiegand E, Ruthel G, Will AB, Geisbert TW, Hevey M, Schmaljohn C, Schmaljohn A, Aman MJ (2002) Lipid raft microdomains: a gateway for compartmentalized trafficking of Ebola and Marburg viruses. J Exp Med 195:593-602

3. Brown MA, Troyer JL, Pecon-Slattery J, Roelke ME, O'Brien SJ (2009) Genetics and pathogenesis of feline infectious peritonitis virus. Emerg Infect Dis 15:1445-1452

4. Dye C, Temperton N, Siddell SG (2007) Type I feline coronavirus spike glycoprotein fails to recognize aminopeptidase $\mathrm{N}$ as a functional receptor on feline cell lines. J Gen Virol 88:1753-1760

5. Glende J, Schwegmann-Wessels C, Al-Falah M, Pfefferle S, Qu X, Deng H, Drosten C, Naim HY, Herrler G (2008) Importance of cholesterol-rich membrane microdomains in the interaction of the $\mathrm{S}$ protein of SARS-coronavirus with the cellular receptor angiotensin-converting enzyme 2. Virology 381:215-221

6. de Groot RJ, Baker SC, Baric R, Enjuanes L, Gorbalenya AE, Holmes KV, Perlman S, Poon L, Rottier PJM, Talbot PJ, Woo PCY, Ziebuhr J (2011) Family Coronaviridae. In: King AMQ, Adams MJ, Carstens EB, Lefkowitz EJ (eds) Virus taxonomy, ninth report of the International Committee on Taxonomy of Viruses. Elsevier Academic Press, San Diego, pp 806-828

7. Herrewegh AA, Smeenk I, Horzinek MC, Rottier PJ, de Groot RJ (1998) Feline coronavirus type II strains 79-1683 and 79-1146 originate from a double recombination between feline coronavirus type I and canine coronavirus. J Virol 72:4508-4514

8. Hohdatsu T, Izumiya Y, Yokoyama Y, Kida K, Koyama H (1998) Differences in virus receptor for type I and type II feline infectious peritonitis virus. Arch Virol 143:839-850
9. Hohdatsu T, Okada S, Ishizuka Y, Yamada H, Koyama H (1992) The prevalence of types I and II feline coronavirus infections in cats. J Vet Med Sci 54:557-562

10. Hohdatsu T, Sasamoto T, Okada S, Koyama H (1991) Antigenic analysis of feline coronaviruses with monoclonal antibodies (MAbs): preparation of MAbs which discriminate between FIPV strain 79-1146 and FECV strain 79-1683. Vet Microbiol 28:13-24

11. Hohdatsu T, Tokunaga J, Koyama H (1994) The role of IgG subclass of mouse monoclonal antibodies in antibody-dependent enhancement of feline infectious peritonitis virus infection of feline macrophages. Arch Virol 139:273-285

12. Ikonen E (2008) Cellular cholesterol trafficking and compartmentalization. Nat Rev Mol Cell Biol 9:125-138

13. Imhoff H, von Messling V, Herrler G, Haas L (2007) Canine distemper virus infection requires cholesterol in the viral envelope. J Virol 81:4158-4165

14. Kapadia SB, Barth H, Baumert T, McKeating JA, Chisari FV (2007) Initiation of hepatitis C virus infection is dependent on cholesterol and cooperativity between CD81 and scavenger receptor B type I. J Virol 81:374-383

15. Kilsdonk EP, Yancey PG, Stoudt GW, Bangerter FW, Johnson WJ, Phillips MC, Rothblat GH (1995) Cellular cholesterol efflux mediated by cyclodextrins. J Biol Chem 270:17250-17256

16. Kummrow M, Meli ML, Haessig M, Goenczi E, Poland A, Pedersen NC, Hofmann-Lehmann R, Lutz H (2005) Feline coronavirus serotypes 1 and 2: seroprevalence and association with disease in Switzerland. Clin Diagn Lab Immunol 12:1209-1215

17. Lee CJ, Lin HR, Liao CL, Lin YL (2008) Cholesterol effectively blocks entry of flavivirus. J Virol 82:6470-6480

18. Lin CN, Su BL, Wang CH, Hsieh MW, Chueh TJ, Chueh LL (2009) Genetic diversity and correlation with feline infectious peritonitis of feline coronavirus type I and II: a 5-year study in Taiwan. Vet Microbiol 136:233-239

19. Motokawa K, Hohdatsu T, Hashimoto H, Koyama H (1996) Comparison of the amino acid sequence and phylogenetic analysis of the peplomer, integral membrane and nucleocapsid proteins of feline, canine and porcine coronaviruses. Microbiol. Immunol 40:425-433

20. Pedersen NC (2009) A review of feline infectious peritonitis virus infection: 1963-2008. J Feline Med Surg 11:225-258

21. Pedersen NC (2014) An update on feline infectious peritonitis: Virology and immunopathogenesis. Vet J 201:123-132

22. Pessin JE, Glaser M (1980) Budding of Rous sarcoma virus and vesicular stomatitis virus from localized lipid regions in the plasma membrane of chicken embryo fibroblasts. J Biol Chem 255:9044-9050

23. Pratelli A, Colao V (2015) Role of the lipid rafts in the life cycle of canine coronavirus. J Gen Virol 96:331-337

24. Rawat SS, Viard M, Gallo SA, Rein A, Blumenthal R, Puri A (2003) Modulation of entry of enveloped viruses by cholesterol and sphingolipids (review). Mol Membr Biol 20:243-254

25. Ren X, Glende J, Yin J, Schwegmann-Wessels C, Herrler G (2008) Importance of cholesterol for infection of cells by transmissible gastroenteritis virus. Virus Res 137:220-224

26. Shiba N, Maeda K, Kato H, Mochizuki M, Iwata H (2007) Differentiation of feline coronavirus type I and II infections by virus neutralization test. Vet Microbiol 124:348-352

27. Sun X, Whittaker GR (2003) Role for influenza virus envelope cholesterol in virus entry and infection. J Virol 77:12543-12551

28. Takano T, Nakano K, Doki T, Hohdatsu T (2015) Differential effects of viroporin inhibitors against feline infectious peritonitis virus serotypes I and II. Arch Virol 160:1163-1170

29. Tekes G, Hofmann-Lehmann R, Bank-Wolf B, Maier R, Thiel HJ, Thiel V (2010) Chimeric feline coronaviruses that encode 
type II spike protein on type I genetic background display accelerated viral growth and altered receptor usage. J Virol 84:1326-1333

30. Tekes G, Hofmann-Lehmann R, Stallkamp I, Thiel V, Thiel HJ (2008) Genome organization and reverse genetic analysis of a type I feline coronavirus. J Virol 82:1851-1859

31. Terada Y, Matsui N, Noguchi K, Kuwata R, Shimoda H, Soma T, Mochizuki M, Maeda K (2014) Emergence of pathogenic coronaviruses in cats by homologous recombination between feline and canine coronaviruses. PLoS One 9:e106534

32. Tewary P, Veena K, Pucadyil TJ, Chattopadhyay A, Madhubala $R$ (2006) The sterol-binding antibiotic nystatin inhibits entry of non-opsonized Leishmania donovani into macrophages. Biochem Biophys Res Commun 339:661-666
33. Thorp EB, Gallagher TM (2004) Requirements for CEACAMs and cholesterol during murine coronavirus cell entry. J Virol 78:2682-2692

34. Tresnan DB, Levis R, Holmes KV (1996) Feline aminopeptidase $\mathrm{N}$ serves as a receptor for feline, canine, porcine, and human coronaviruses in serogroup I. J Virol 70:8669-8674

35. Van Hamme E, Dewerchin HL, Cornelissen E, Verhasselt B, Nauwynck HJ (2008) Clathrin- and caveolae-independent entry of feline infectious peritonitis virus in monocytes depends on dynamin. J Gen Virol 89:2147-2156

36. Viard M, Parolini I, Sargiacomo M, Fecchi K, Ramoni C, Ablan S, Wang JM, Blumenthal R (2002) Role of cholesterol in human immunodeficiency virus type 1 envelope protein-mediated fusion with host cells. J Virol 76:11584-11595 